\title{
MN4-based G4-Ligands as Potential Antitumor Agents: A Review
}

\author{
Vivek Sharma $1, *$ (D) \\ 1 Department of Chemistry, GLA University, Mathura, India \\ * Correspondence: vivek.sharma@gla.ac.in;
}

Scopus Author ID 55463048200

Received: 23.03.2021; Revised: 20.05.2021; Accepted: 23.05.2021; Published: 13.08.2021

\begin{abstract}
Cisplatin-based metal drugs have been widely used clinically as anticancer agents. However, these drugs also harm ordinary tissues because cisplatin kills cancer cells by attacking genomic DNA. Therefore, it has been shown that cisplatin-based metal drugs have some serious side effects that cannot be avoided. In order to replace the target site of genomic DNA, G-quadruplex nucleic acid is considered to be an alternative and attractive target for anticancer agents because G-quadruplex always folds into a parallel topology and is, therefore, more important than DNA. This review discussed the recent advancements in the rational design and the development of metal complexes containing anticancer drugs to interact and stabilize or cleave the G4 structure selectively. Further, we also highlighted the G4-interacting transition metal complexes, interacting modes, and their potentials to serve as anticancer drugs in the medical field. The significance of this survey lies in designing the metallodrugs from the most fundamental characteristic of electronic structural engineering to an increasingly reasonable dimension of bio-science.
\end{abstract}

Keywords: cisplatin; macrocyclic complexes; anticancer drugs; G-quadruplex; DNA/RNA.

(c) 2021 by the authors. This article is an open-access article distributed under the terms and conditions of the Creative Commons Attribution (CC BY) license (https://creativecommons.org/licenses/by/4.0/).

\section{Introduction}

There is a developing eagerness for the utilization of Platinum (Pt) based chelates as restorative agents. These Pt-based chelates and their analogs were observed to be the most effective chemotherapeutic potential models in treating tumor treatment [1]. However, nephrotoxicity, ototoxicity, and other genuine side effects of these compounds hindered their further use. Several Pt-based compounds can also cooperate with genetic DNA structure, exhibiting destruction of few inside procedures like transcriptions and translations, which could be considered the cause of tumor cell demise eventually. Further, it was observed that this sort of communication of metallo-drugs with receptors can't recognize ordinary and unusual cells, causing a few genuine detriments as far as a reaction on typical cells tissues [2,3]. Subsequently, there is a need to design some particular potential models that possess different actions of mechanism and evaluate the cutting-edge synchronous innovation that would firmly contribute to the advancements here $[4,5]$.

Further, investigations on several potential natural targets instead of genomic DNA can be considered promising receptors to design particular metallo-drugs. In this way, Gquadruplex, a nucleic acid, was perceived as an organic focus for the activity of metallo-drugs. Usually, self-assembly of guanine-rich nucleic corrosive arrangements came about the development of G-quadruplex. It shows huge organic roles in regulating the quality translation 
in advertiser regions [6-11]. However, the duplex DNA translation is rapidly loosened up to discharge the G-rich single strand from the integral C-rich strand.

G4-RNA is much more stable than the equivalent G4-DNA sequence and is always topologically folded in parallel and circulates throughout the cell containing the cytoplasm. Therefore, it is easier to access centrally than DNA [12-15]. Since the G-quadruplex is a fascinating structure, it is far from the stacked G-quadruplex's appearance. There are three kinds of circles and four depressions, where these auxiliary protrusions and double-stranded body DNA are not exactly the same. In addition, in terms of the number of RNA arrangements, it is synthetically specific. Moreover, due to the presence of 2'-hydroxyl bundles, it can be folded into a G-quadruplex structure in vitro [16]. Therefore, in these practical highlights, Gquadruplex RNA is also considered a potential focus of anticancer metallo-drugs. The recent literature model meets the inspection requirements, focusing on the design of highly selective RNA metallo-drugs for target G-quadruplex RNA [17,18]. Recently, studies have suggested that the development of G-quadruplexes is related to human diseases (such as diseases, HIV, and diabetes) $[19,20]$, and the grouping of these structures is currently regarded as a recovery target $[21,22]$

Interestingly, the G4-ligands can effectively communicate with G-quadruplexes via the side connection with duplex DNA [23,24]. Thus, G-quadruplex has attracted the scientific community to utilize this idea to discover novel effective anticancer agents with well-defined mechanisms. Metal chelates are proficient in framing oxidize guanine nucleic corrosive by abstracting ribosyl hydrogen that is separate oxidative DNA. On the other hand, $\mathrm{N}_{4-}$ macrocyclic complexes were likewise observed to be compelled to assume the real mechanism of DNA interaction with these compounds and found that this interaction depends on the substituent on a macrocyclic framework and positive charge on the metal ion [25-28].

This review focused on the basic highlights of various DNA and RNA G-quadruplexes and outlined the G-quadruplex-ligand partnership. This may give an important reference to metallo-drug structure and acknowledgment focusing on G-quadruplexes and clarifying the interaction with the G-quadruplexes. Further, the exact and recent advancements on macrocyclic complexes as G4-ligands and their coupling modes with the G-quadruplex have also been highlighted.

\section{The Implications of G4-Ligands}

G-quadruplex has gotten much interest in recent decades because of its potential role in DNA replication, transcriptional guideline, and genome stability [29-33]. Small molecular frameworks which can effectively interact with G-quadruplex over the duplex nucleic acids are named G4-ligands. The investigations on G4-ligands have received a dynamic and promising interest in the field of designing metallo-anticancer-drugs [34,35]. For instance, Quarfloxin (CX3543) drug is the G4-ligands and has been recognized as a stage II as far as clinical preliminaries with the end goal of neuroendocrine and carcinoid tumors treatment.

Besides, $\mathrm{N}_{4}$-macrocyclic complexes and metal chelates as G4-ligands could be intrigued by their high affinity and specificity for association with quadruplex nucleic acids [36,37]. The remarkable basic highlights, formal charge on metal ions, and attractive properties of $\mathrm{N}_{4}$-macrocyclic complexes are the key focal points and make them a perfect contender to develop the G4-ligands. Further, their planar, octahedral, tetragonal pyramidal, and so on geometries can offer various activity modes. For example, a planar macrocycle favors $\pi-\pi$ stacking mode of association with G-quartets, trailed by end-stacking or intercalations. 
Furthermore, the elective interaction methods, such as groove official, electrostatic collaborations, and direct coordination through phosphate spine, were also watched.

\section{G-Quadruplex Targeting Metal Complexes}

\subsection{Cisplatin derivatives-platination of G-quadruplex.}

Cisplatin and its derivatives were generally considered the best anticancer metallo-drug in the clinical phase; however, their few side effects limit their further use. Therefore, it is necessary to find an alternative class of metallo-drug with high selectivity and activity. Cisplatin derivatives containing chlorine and water ligands are more likely to interact with G4 DNA nucleobases in co-appointment design as a solitary site. While, the other auxiliaries like phenyl rings in the structure of these derivatives are truly appropriate for the $\pi$ - $\pi$ stacking interaction with the G-quadruplex by means of non-covalent interaction mode [38].

Bertrand $\mathrm{H}$ et al., [39] synthesized novel Pt(II)-based complexes (Figure 1) and found that these complexes can interact with the human telomeric G-quadruplex-DNA without much interface stretch pursued by various interaction modes, for example, covalently and noncovalent interactions. The terpyridine-platinum-based complex, represented by 'Pt-tpy', showed the covalent interaction with quadruplex-DNA. Another compound, Pt-quinacridine, represented as 'Pt-MPQ', crossovers to cooperate with quadruplex-DNA through a double noncovalent/covalent interaction mode.

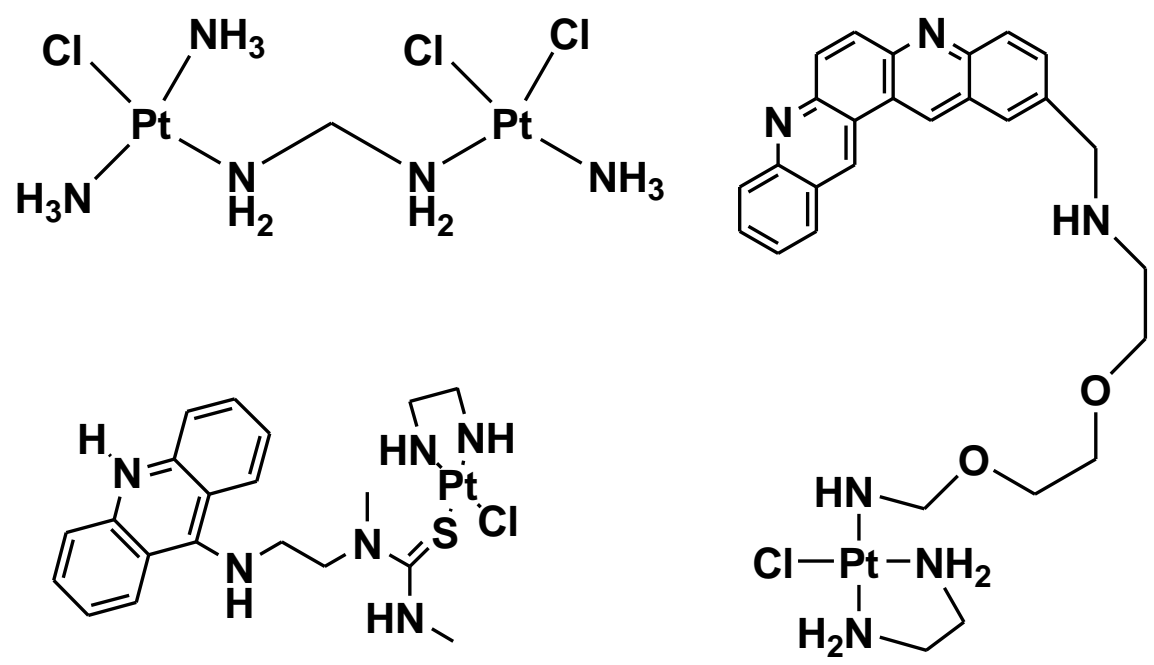

Figure 1. Molecular Structure of Pt (II) complex.

Qi-Pin Qin et al., [40] reported a Pt(II) complex with phenanthroline moieties. This complex showed specific cytotoxicity for tumor cells. This selectivity could be achieved by interfering with "telomerase movement" via the "c-myc-quadruplex and caspase initiation" relationship. In addition, planar and non-planar polydentate macrocyclic complexes are another class of anticancer drugs, for example, square planar Pt(II)-phenanthroline types compounds. In these complexes, phenanthroline moiety can be substituted by bipyridine, phenylpyridine, dipyridine phenazine, and these ligand moieties incorporated with $\mathrm{Pt}(\mathrm{II})$ showed a significant role in DNA controlling applications, while their square-planar geometry exhibited the $\pi-\pi$ stacking with G-quartets. In addition, it is reported that the ligands encompassing $\pi$ surface support the G4-interaction. For instance, Pt(II) complexes with bis-phenanthroline and phenanthroline-ethylenediamine ligands balanced out the G-quadruplex structures, appearing strong interaction bis-bipyridine and bipyridine-ethylenediamine derivatives. Generally, a full- 
ring $\pi$-delocalized surface with aromatic side groups proved that the affinity and selectivity to G4 interaction were improved significantly [41-47]. Figure 2 showed several Pt(II) compounds with bisphenanthroline or phenanthroline-ethylenediamine.

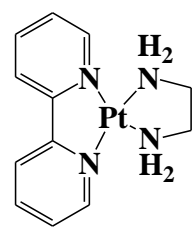<smiles></smiles>

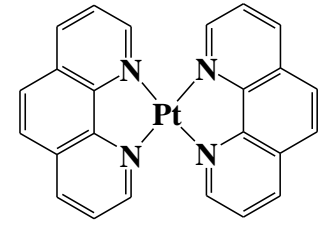

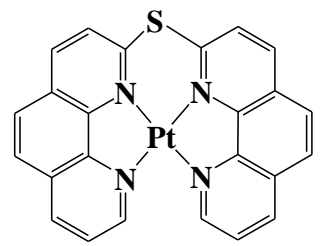

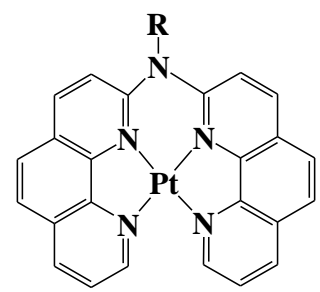

Figure 2. Molecular Structure of Pt(II) complex with phenanthroline subordinate.

\section{2. $N_{4}$-macrocyclic and its derivatives.}

$\mathrm{N}_{4}$-macrocyclic complexes like phthalocyanines and porphyrins have a large aromatic surface that can encourage the end-stacking interaction with the terminal G-quartets. Membrino An et al. [48] incorporated a guanidine-modified phthalocyanine (GPcs) framework and used it as a G4-DNA ligand, and the quality of the modulator was improved. In this investigation, many cells were absorbed by living cells and suffocated the activity of luciferase. These results are reliable under the advertisers' inhibition of G-quadruplex intervention and inspire further research on the anticancer ability of GPcs. L Ren et al. [49] reported octa-cation zinc phthalocyanine (ZnPc), which is a very good G-quadruplex DNA stabilizer (Figure 3).

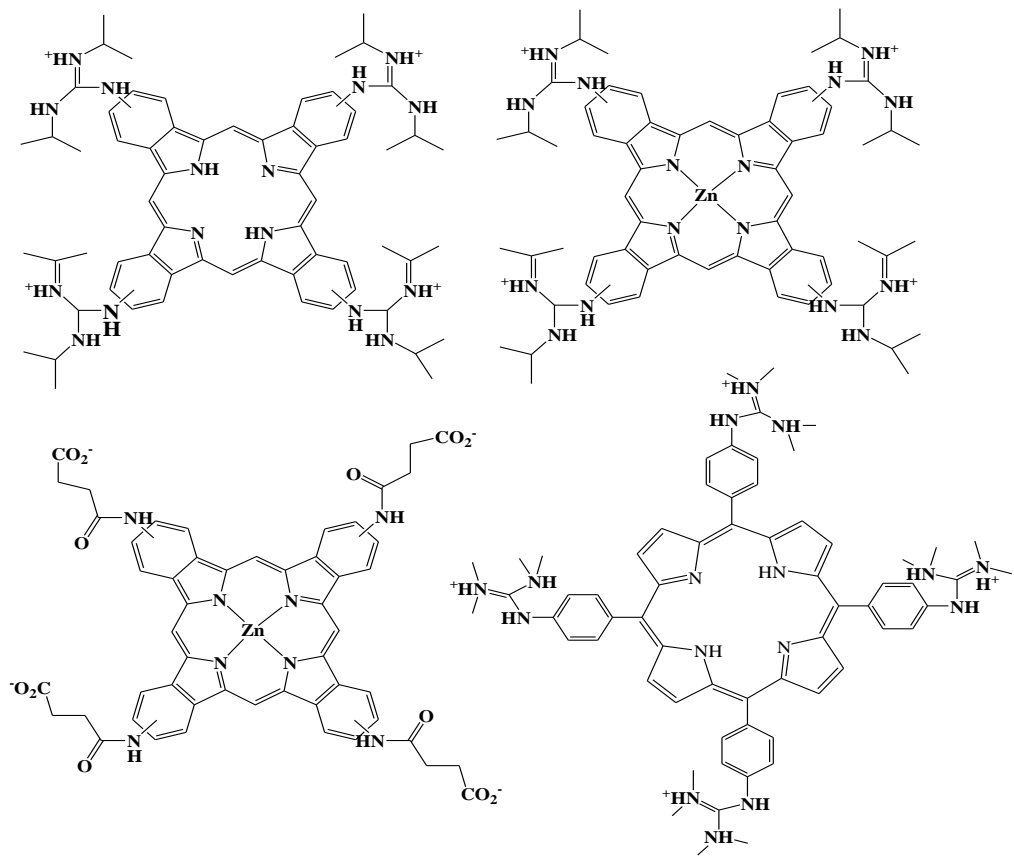

Figure 3. Molecular Structure of Octa-cationic/Tetra-cationic phthalocyanines.

On the other hand, $\mathrm{Ni}^{\mathrm{II}} \mathrm{TMPyP}_{4}$ macrocyclic complex was observed to be an intense inhibitor of telomerase, appearing to restrict affinity for G4 DNA as a contrast with the duplex DNAs. Likewise, $\mathrm{Mn}^{\mathrm{III}} \mathrm{TMPyP}_{4}$ macrocyclic complex demonstrated the comparative 
telomerase hindrance power to the free TMPyP4 macrocyclic ligand, however, the Mn ${ }^{\mathrm{III}}$ TMPyP4 macrocyclic complex indicated 10-fold better selectivity for the G4-quadruplex over DNA duplex [50,51]. Further, $\mathrm{Mn}^{\mathrm{III}}$ substitution by $\mathrm{Zn}^{\mathrm{II}}$ metal ion in this macrocyclic framework restrains the selectivity and power for quadruplex just as the telomerase [52] (Fig. 4).

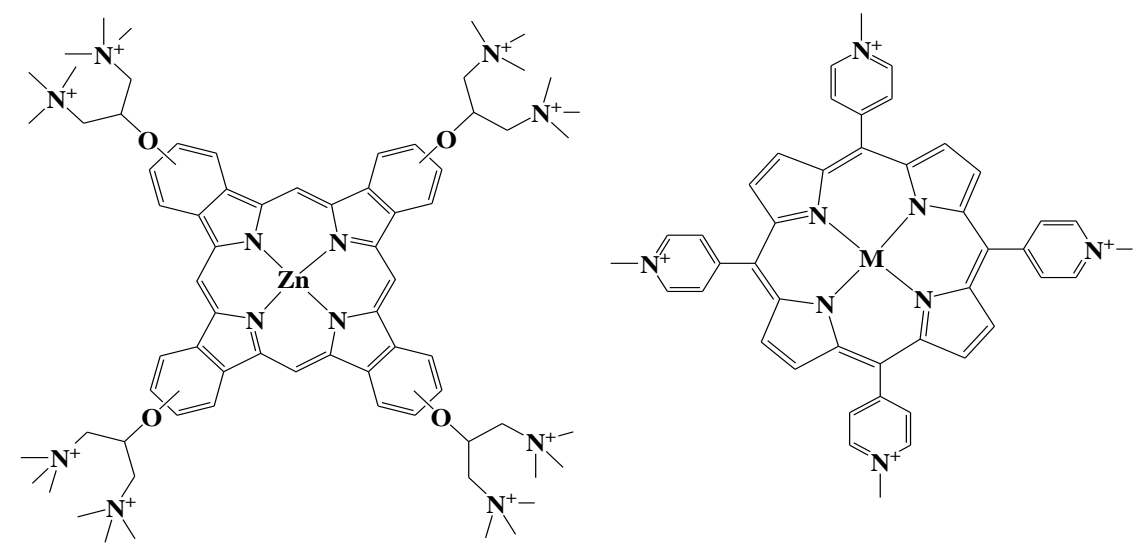

Figure 4. Molecular Structure of TMPyP4 macrocyclic complex.

These strategies showed that the planar macrocyclic complexes and the high charged side chains are the potential agents to telomerase and increase the G-quadruplex's good effect. Because of their special geometric structure and electronic structure can effectively regulate metal ions that change in higher oxidation states. Therefore, corroles are another type of adaptive porphyrin derivative. In this way, the progress of $\mathrm{Cu}^{\mathrm{II}}$ and $\mathrm{Mn}^{\mathrm{III}}$ corroles (Fig. 5) is considered effective G4 ligands. It has been observed that these complexes are strong telomerase inhibitors [53-55]. Surprisingly, these macrocyclic complexes have a saddle-shaped geometry that is generally opposite to planar metalloporphyrins.

The $\mathrm{Mn}^{\mathrm{III}}$ corrole type macrocyclic compound substituted with methylpyridinium is another type of skeleton $[56,58]$ with special geometry and a high degree of electronic insufficiency, exhibiting high selectivity towards the G4 on double-stranded DNA. As shown by PCR experiments, these complexes effectively activate and balance Tel and c-myc Gquadruplex DNA. Further, the $\mathrm{Cu}^{\mathrm{II}}$ macrocyclic complex was changed by introducing three meso-substituted phenyl ring pyridinium or quaternary ammonium groups on its framework and used as a G4 ligand [59-61].

This change builds the quantity of cationic charges, expanding the electrostatic cooperation to the already contrarily charged DNA spine. The PCR examinations showed that these macrocyclic mixtures can settle G4 well in the miniature molar $\mathrm{Na}^{+}$centering reach, and some of them energize the antiparallel G4 geography.
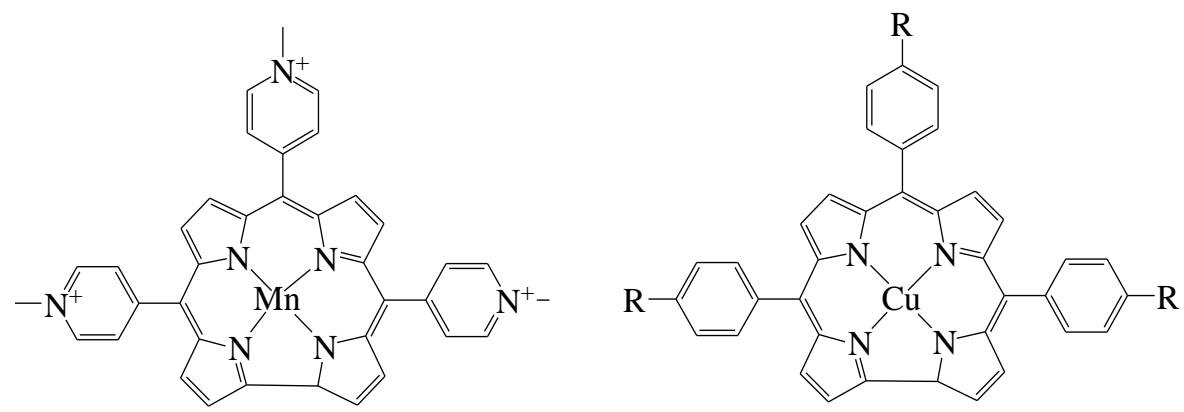

Figure 5. Molecular structure of corrole macrocycles. 


\section{The Interaction Model of Macrocyclic Complexes-based G4-Ligand with G- Quadraplex}

The advances on the "G-quadruplexes" have recently evidenced that macrocyclic complexes play a significant role in DNA replication, modulation on transcription, genome stability [62-65], and cancer cells. Consequently, "G-quadruplexes" were observed to be a potent anticancer. Considering this fact, scientists have focussed on the development of a small molecular inducer and "G-quadruplexes" stabilizer [66]. To meet this, the comprehension of restricting the design of "G-quadruplexes" with the G4-ligands is vital. Until now, the computational and biochemical investigations indicated the primarily three sorts of proficient restricting methods of the "G-quadruplexes" with the G4-ligands (i) stacking on the terminal G-quadruplicates of a "G-quadruplexes" [67], (ii) intercalation between G-quadruplicates of a "G-quadruplexes" [68], and (iii) association with the scores/circles/spine of a "Gquadruplexes" [69].

\subsection{Stacking on the terminal G-quadruplicates.}

Macrocyclic complexes with aromatic moieties mostly preferred the $\pi-\pi$ interaction with the G-quadruples [70]. The positively charged metal ions in macrocyclic complexes are responsible for the interaction with G-quadruple duplex terminally. Therefore, these macrocyclic complexes' strategies depend on G4-ligand with "G-quadruplexes" by means of $\mathrm{p}-\mathrm{p}$ stacking, electrostatic, hydrophobic, and van der Waals forces. Because of these forces, the huge aromatic moieties showed high explicitness for G4-DNA over duplex DNA duplex [71-73]. TMPyP 4 is a run-of-the-mill case of macrocyclic complexes based on G4-ligand, which contain a fragrant focal ring and were generally utilized as "G-quadruplexes" folios.

Also, the four methylated N-coordination in TMPyP4 skeleton gave an advantage in improving the water solvency and p-stacking capacity. Further investigations demonstrated that the TMPyP4 porphyrin ring was stacked on one terminal G-quadruplicate of the "Gquadruplexes" [74]. TMPyP4 with high solidness demonstrates a more prominent reactivity for "G-quadruplexes" and poor selectivity for "G-quadruplexes" over duplex DNA [75,76]. Further, $\mathrm{Mn}(\mathrm{III})$ porphyrin analogs were investigated and found that the "stacking of porphyrin" on the terminal G-quadruplicates and the intercalation of four adaptable arms with the notches were obligated for both high reactivity and great selectivity for "G-quadruplexes" [77-81].

This ligand can tie to a "G-quadruplexes" through a relationship of two Gquadruplicates and embrace round compliance. Further, a chiral cyclic helicene with a folio was accounted for that displayed enantio-specific ability towards the "G-quadruplexes" and associated with a TTA linker. The cyclic helicene displayed strong inhibitory movement against telomerase and these outcomes confirmed-idea to little particle inhibitors of telomerase [82].

\subsection{Intercalating between G-quadruplicates.}

It is a notable thought that macrocyclic complexes can introduce between DNA base pairs. The hypochromic and bathochromic shift in the UV spectra of the intercalated macrocyclic complexes was clearer than those of the non-intercalated macrocycles among ligands and "G-quadruplexes" [83]. 
Lubitz et al., reported that without $\mathrm{K}^{+}$, TMPyP4 macrocycle intervened between neighboring G-quadruplicates of G4-duplex [84], trailed by the association at 1:2 stoichiometry via pi-pi stacking. While, within sight of $\mathrm{K}^{+}$, it cooperated with $\mathrm{G}$-duplex through the side or/end stacking instead of the intercalation mode, and this is a great concurrence with the consequences of different gatherings $[85,86]$. The outcomes recommend that the $\mathrm{TMPyP}_{4}$ molecules embed into every G-quadruplicate layer without making any significant changes for neighboring systems that are aggressive. However, the end stacking and depression restricting modes don't exist. Furthermore, the investigations indicated that TMPyP4 cooperated with the "G-quadruplexes" of d(T4G4) through intercalation at a low [TMPyP4]/[G-DNA molecule] ratio [87]. Unless there are other options referenced, papers offered the NMR spectroscopy information and precious stone structures of the edifices; subsequently, there is no definitive proof to bolster the intercalation mode emphatically. These remaining studies to further investigate the conceivable restricting modes between the ligands and the "G-quadruplexes" is still needed.

\section{Concluding Remarks}

This review summarized the metal complexes based on G4-ligands, indicating their applications as DNA groove binder, DNA cleavage, and anticancer agents. G4 nucleic acids have acquired a lot of attention as strong clinical agents for the development of another class of anticancer agents. The compounds that can distinguish and interrelate with the G-quadruplex with higher intercalation tendency and high selectivity are named G4-ligands. These G4ligands as G-quadruplex stabilizers, telomerase inhibitors, and DNA cleavage agents were deliberately analyzed during the most recent couple of years. Likewise, the recent development on G4-ligands has opened the doors for a malignant growth in chemotherapy. In addition, these G4-ligands hold the key to development. Usually, different metals connected with similar ligands can deliver metal edifices within general assorted "G4 ligand" properties. The interactions between the metal complexes and G-quadruplex have been characterized by several biophysical methods describing the strength and specificity of these "G4-ligand" interactions. The comprehension of metal complexes containing "G4-ligands" reveals three fundamental parts, G-quadruplex, fragment, and G-quadruplex ring, which are responsible for the linking with the main active site in DNA duplex (intercalating the coupling mode). The presence of functional side chains on the framework of metal complexes facilities their interaction with DNA base pairs via intercalation mode.

In addition, a couple of binding modes can take place at an identical time, however, groove/ring binding is typically an auxiliary mode of interaction, generally pushed by way of interacting with the predominant mode of the ultimate stack. Only a few bimetallic Pt (II), bimetallic $\mathrm{Ru}$ (II) and macrocyclic $\mathrm{Zn}$ (II) complexes use grooves and rings as the fundamental identification methods. This affords a brilliant proposal for the plan of the subsequent era of G4 ligands, which will be counted much less on the generic G quartet, and greater on unique groove/loop recognition. Moreover, $\pi-\pi$ stacking and groove/ring bonding, steel complexes containing unstable corporations $\left(\mathrm{Cl}, \mathrm{H}_{2} \mathrm{O}\right.$, etc.) can additionally coordinate the metallic core at once with the G4 DNA nucleobase, comparable to cisplatin for double-stranded DNA of electroplating. This kind of coordination takes place at a single nucleotide, which is guanine in most cases or leads to cross-linking of two nucleobases, which might also beautify the affinity and specificity of the steel complicated for G4 DNA. 
However, the development of G4-ligands has been dominated through in vitro biophysics and biochemical research, and the perception of G4-ligand pastime and selectivity in the in vivo surroundings stays an important challenge. After so many years, only one promising in vivo G4-ligand Quarfloxin entered a segment II scientific trial to treat neuroendocrine and carcinoid tumors. This can also open up new approaches to use metalcontaining G4 ligands as eye-catching catalytic markers in biosensing. In short, the improvement of metal-containing G4-ligands as new anticancer capsules is a swiftly creating field. Despite some progress, to date, most metal-containing G4-ligands have no practical druglike structure, and their utility in vivo is nevertheless very rare. Therefore, in addition, improvement in this discipline is anticipated to be the center of attention on clinical research, and in the subsequent few years, we hope to see a new technology of metal-containing G4 ligands enter medical trials.

\section{Funding}

NA.

\section{Acknowledgments}

The author pays his thankfulness to the management of GLA University, Mathura (India), for all kinds of support related to work. The author thanks Dr. Anuj Kumar (Assistant Professor, Department of Chemistry, GLA University) for providing his precious suggestions during this work.

\section{Conflicts of Interest}

No conflict of interest.

\section{References}

1. Sonja, M.-D.; Jelena, P.; Andjelka, M.I.; Tibor, S.; Ivanka, M.; Vladimir, T. Current Development of Metal Complexes with Diamine Ligands as Potential Anticancer Agents. Curr. Med. Chem. 2020, 27, 380-410, https://doi.org/10.2174/0929867325666181031114306.

2. Zhou, J.; Kang, Y.; Chen, L.; Wang, H.; Liu, J.; Zeng, S.; Yu, L. The Drug-Resistance Mechanisms of Five Platinum-Based Antitumor Agents. Front. Pharmacol. 2020, 11, 343, https://doi.org/10.3389/fphar.2020.00343.

3. Ho, Y.-P.; Au-Yeung, S.C.F.; To, K.K.W. Platinum-based anticancer agents: Innovative design strategies and biological perspectives. Med. Res. Rev. 2003, 23, 633-655, https://doi.org/10.1002/med.10038.

4. Velugula, K.; Kumar, A.; Chinta, J.P. Nuclease and anticancer activity of antioxidant conjugated terpyridine metal complexes. Inorg. Chim. Acta 2020, 507, 119596, https://doi.org/10.1016/j.ica.2020.119596.

5. Findik, M.; Ucar, A.; Türkkan, E.; Pehlivanoglu, S.; Ozcan, E. Synthesis of anti-4phenoxyphenylaminoglyoxime and its some transition metal complexes: Spectral, DFT, electrochemical and anticancer activity studies. JMoSt 2020, 1215, 128190, https://doi.org/10.1016/j.molstruc.2020.128190.

6. Patel, D.J.; Phan, A.T.; Kuryavyi, V. Human telomere, oncogenic promoter and 5'-UTR G-quadruplexes: diverse higher order DNA and RNA targets for cancer therapeutics. NAR 2007, 35, 7429-7455, https://doi.org/10.1093/nar/gkm711.

7. Burge, S.; Parkinson, G.N.; Hazel, P.; Todd, A.K.; Neidle, S. Quadruplex DNA: sequence, topology and structure. NAR 2006, 34, 5402-5415, https://doi.org/10.1093/nar/gkl655.

8. Campbell, N.H.; Neidle, S. G-Quadruplexes and Metal Ions. In Interplay between Metal Ions and Nucleic Acids, Sigel, A., Sigel, H., Sigel, R.K.O., Eds. Springer Netherlands: Dordrecht, 2012, https://doi.org/10.1007/978-94-007-2172-2. 
9. Largy, E.; Mergny, J.-L.; Gabelica, V. Role of Alkali Metal Ions in G-Quadruplex Nucleic Acid Structure and Stability. In The Alkali Metal Ions: Their Role for Life, Sigel, A., Sigel, H., Sigel, R.K.O., Eds. Springer International Publishing: Cham, 2016; 203-258, https://doi.org/10.1007/978-3-319-21756-7_7.

10. Biffi, G.; Tannahill, D.; McCafferty, J.; Balasubramanian. Quantitative visualization of DNA G-quadruplex structures in human cells. Nat Chem 2013, 5, 182-186. https://doi.org/10.1038/nchem.1548.

11. Qin, Y.; Hurley, L.H. Structures, folding patterns, and functions of intramolecular DNA G-quadruplexes found in eukaryotic promoter regions. Biochimie 2008, 90, 1149-1171, https://doi.org/10.1016/j.biochi.2008.02.020.

12. Fernando, H.; Reszka, A.P.; Huppert, J.; Ladame, S.; Rankin, S.; Venkitaraman, A.R.; Neidle, S.; Balasubramanian, S. A Conserved Quadruplex Motif Located in a Transcription Activation Site of the Human c-kit Oncogene. Biochemistry 2006, 45, 7854-7860, https://doi.org/10.1021/bi0601510.

13. Rankin, S.; Reszka, A.P.; Huppert, J.; Zloh, M.; Parkinson, G.N.; Todd, A.K.; Ladame, S.; Balasubramanian, S.; Neidle, S. Putative DNA Quadruplex Formation within the Human c-kit Oncogene. J. Am. Chem. Soc. 2005, 127, 10584-10589, https://doi.org/10.1021/ja050823u.

14. Siddiqui-Jain, A.; Grand, C.L.; Bearss, D.J.; Hurley, L.H. Direct evidence for a G-quadruplex in a promoter region and its targeting with a small molecule to repress c-MYC transcription. Proceedings of the National Academy of Sciences 2002, 99, 11593, https://doi.org/10.1073/pnas.182256799.

15. Rangan, A.; Fedoroffand, O. Y.; Hurley, L. H. Induction of Duplex to G-quadruplex Transition in the c-myc Promoter Region by a Small Molecule. J Biol Chem 2001, 276, 4640-4646, https://doi.org/10.1074/jbc.M005962200.

16. Biffi, G.; Antonio, M. Di.; Tannahill, D.; Balasubramanian, S. Visualization and selective chemical targeting of RNA G-quadruplex structures in the cytoplasm of human cells. Nat Chem 2014, 6, 75 - 80. https://doi.org/10.1038/nchem.1805

17. Simonsson, T. G-Quadruplex DNA Structures Variations on a Theme. Biol Chem 2001, 382, 621 - 628, https://doi.org/10.1515/BC.2001.073.

18. Parkinson, G. N.; Lee, M. P.; Neidle, S. Crystal structure of parallel quadruplexes from human telomeric DNA. Nature 2002, 417, 876 - 880, https://doi.org/10.1038/nature755.

19. Wang, Y.; Patel, D. J. Solution structure of the human telomeric repeat d[AG3(T2AG3)3] G-tetraplex. Structure 1993, 1, 263 - 282, https://doi.org/10.1016/0969-2126(93)90015-9.

20. Sen, D.; Gilbert, W. Formation of parallel four-stranded complexes by guanine-rich motifs in DNA and its implications for meiosis. Nature 1988, 334, 364-366, https://doi.org/10.1038/334364a0.

21. Mergny, J. L.; Cian, A. D.; Amrane, S.; Silva, M. W. Kinetics of double-chain reversals bridging contiguous quartets in tetramolecular quadruplexes. Nucleic Acids Res 2006, 34, $2386 \quad-\quad 2397$, https://doi.org/10.1093/nar/gk1098.

22. Krishnan-Ghosh, Y.; Liu, D.; Balasubramanian, S. Formation of an Interlocked Quadruplex Dimer by d(GGGT). J Am Chem Soc 2004, 126, 11009-11016, https://doi.org/10.1021/ja049259y.

23. Kato, Y.; Ohyama, T.; Mita, H.; Yamamoto, Y. Dynamics and Thermodynamics of Dimerization of Parallel G-Quadruplexed DNA Formed from d(TTAGn) $(\mathrm{n}=3-5)$. J Am Chem Soc 2005, 127, 9980-9981, https://doi.org/10.1021/ja050191b.

24. Arora, A.; Maiti, S. Differential Biophysical Behavior of Human Telomeric RNA and DNA Quadruplex. $J$ Phys Chem B 2009, 113, 10515-10520, https://doi.org/10.1021/jp810638n.

25. Agarwal, T.; Jayaraj, G.; Pandey, S. P.; Agarwala, P.; Maiti, S. RNA G-Quadruplexes: G-quadruplexes with “U” Turns. Curr Pharm Des 2012, 18, 2102-2111, https://doi.org/10.2174/138161212799958468.

26. Xu, Y.; Komiyama, M. Structure, function and targeting of human telomere RNA. Methods, 2012, 57, 100105. https://doi.org/10.1016/j.ymeth.2012.02.015.

27. Tang, C. F.; Shafer, R. H. Engineering the Quadruplex Fold: Nucleoside Conformation Determines Both Folding Topology and Molecularity in Guanine Quadruplexes. J Am Chem Soc 2006, 128, 5966-5973, https://doi.org/10.1021/ja0603958.

28. Murat, P.; Singh, Y.; Defrancq, E. Methods for investigating G-quadruplex DNA/ligand interactions. Chem Soc Rev 2011, 40, 5293-5307, https://doi.org/10.1039/C1CS15117G.

29. Ho, Y.-P.; Au-Yeung, S. C. F.; To, K. K. W. Platinum-based anticancer agents: Innovative design strategies and biological perspectives. Med Res Rev 2003, 23, 633-655, https://doi.org/10.1002/med.10038.

30. Bruijnincx, P. C. A.; Sadler, P. J. New trends for metal complexes with anticancer activity. Curr Opin Chem Biol 2008, 12, 197-206, https://doi.org/10.1016/j.cbpa.2007.11.013. 
31. Gellert, M.; Lipsett, M. N. Davies D. R, Helix formation by Gguanylic acid. Proc. Natl. Acad. Sci. U. S. A. 1962, 48, 2013-2018, https://doi.org/10.1073/pnas.48.12.2013.

32. Rao, L.; Dworkin, J. D.; Nell, W. E.; Bierbach, U. Interactions of a platinum-modified perylene derivative with the human telomeric G-quadruplex, J. Phys. Chem. B 2011, 115, 13701-13712, https://doi.org/10.1021/jp207265s.

33. Burge, S.; Parkinson, G. N.; Hazel, P.; Todd, A. K.; Neidle, S. Quadruplex DNA: sequence, topology and structure. Nucleic Acids Res 2006, 34, 5402-5415, https://doi.org/10.1093/nar/gk1655.

34. Georgiades, S. N.; Abd Karim, N. H.; Suntharalingam, K.; Angew, R. Interaction of Metal Complexes with G-Quadruplex DNA. Chem Int Ed 2010, 49, 4020-4034, https://doi.org/10.1002/anie.200906363.

35. Campbell, N.; Collie, G. W.; Neidle, S. Crystallography of DNA and RNA G-Quadruplex Nucleic Acids and Their Ligand Complexes. Current Protocols in Nucleic Acid Chemistry, John Wiley \& Sons, Inc., 2012. https://doi.org/10.1002/0471142700.nc1706s50.

36. Papadopoulos, K.; Mita, A.; Ricart, A; Hufnagel, D.; Northfelt, D.; Von Hoff, D.; Darjania, L.; Lim, J.; Padgett, C.; Marschke, R. Pharmacokinetic findings from the phase I study of Quarfloxin (CX-3543): a protein-rDNA quadruplex inhibitor, in patients with advanced solid tumours. Am Assoc Cancer Res 2007, 6, B93-B93.

37. Zhang, J.; Zhang, F.; Li, H.; Liu, C.; Xia, J.; Ma, L.; Chu, W.; Zhang, Z.; Chen, C.; Li, S.; Wang, S. Recent Progress and Future Potential for Metal Complexes as Anticancer Drugs Targeting G-quadruplex DNA. Curr Med Chem 2012, 19, 2957-2975.

38. Bertrand, H.; Monchaud, D.; De Cian, A.; Guillot, R.; Mergny, J.-L.; Teulade-Fichou, M.-P. The importance of metal geometry in the recognition of G-quadruplex-DNA by metal-terpyridine complexes. Org Biomol Chem 2007, 5, 2555-2559, https://doi.org/10.1039/B708635K.

39. Bertrand, H.; Bombard, S.; Monchaud, D.; Teulade-Fichou, M.-P. A platinum-quinacridine hybrid as a Gquadruplex ligand. J Biol Inorg Chem 2007, 12, 1003-1014, https://doi.org/10.1007/s00775-007-0273-3.

40. Huppert, J. L. Four-stranded nucleic acids: structure, function and targeting of G-quadruplexes. Chem Soc Rev 2008, 37, 1375-1384, https://doi.org/10.1039/B702491F.

41. Ang, D.L.; Kelso, C.; Beck, J.L.; Ralph, S.F.; Harman, D.G.; Aldrich-Wright, J.R. A study of Pt (II)phenanthroline complex interactions with double-stranded and G-quadruplex DNA by ESI-MS, circular dichroism, and computational docking. J Biol Inorg Chem 2020, 26, 1-2, https://doi.org/10.1007/s00775020-01773-4.

42. Abazari, O.; Shafaei, Z.; Divsalar, A.; Eslami-Moghadam, M.; Ghalandari, B.; Saboury, A.A; Moradi, A. Interaction of the synthesized anticancer compound of the methyl-glycine 1, 10-phenanthroline platinum nitrate with human serum albumin and human hemoglobin proteins by spectroscopy methods and molecular docking. J Iran Chem Soc 2020, 17, 1601-1614, https://doi.org/10.1007/s13738-020-01879-1.

43. Backman-Blanco, G.; Valdés, H.; Ramírez-Apan, M.T.; Cano-Sanchez, P.; Hernandez-Ortega, S.; Orjuela, A.L.; Alí-Torres, J.; Flores-Gaspar, A.; Reyes-Martínez, R.; Morales-Morales, D. Synthesis of Pt (II) complexes of the type [Pt (1, 10-phenanthroline) (SArFn) 2] (SArFn=SC6H3-3, 4-F2; SC6F4-4-H; SC6F5). Preliminary evaluation of their in vitro anticancer activity. J Inorg Biochem, 2020, 211,111206, https://doi.org/10.1016/j.jinorgbio.2020.111206.

44. Barry, N. P. E.; Abd Karim, N. H.; Vilar, R.; Therrien, B. Interactions of ruthenium coordination cubes with DNA. Dalton Trans. 2009, 4, 10717-10719, https://doi.org/10.1039/B913642H.

45. Li, Q.; Zhang, J.; Yang, L.; Yu, Q.; Chen, Q.; Qin, X.; Le, F.; Zhang, Q.; Liu, J. Stabilization of G-quadruplex DNA and inhibition of telomerase activity studies of ruthenium (II) complexes. J Inorg Biochem 2014, 130, 122-129, https://doi.org/10.1016/j.jinorgbio.2013.10.006.

46. Xia, Y.; Chen, Q.; Qin, X.; Sun, D.; Zhang, J.; Liu, J. Studies of ruthenium(ii)-2,2'-bisimidazole complexes on binding to G-quadruplex DNA and inducing apoptosis in HeLa cells. New J. Chem 2013, 37, 3706-3715, https://doi.org/10.1039/C3NJ00542A.

47. Chen, X.; Wu, J.-H.; Lai, Y.-W.; Zhao, R.; Chao, H.; Ji, L.-N. Targeting telomeric G-quadruplexes with the ruthenium(ii) complexes [Ru(bpy)2(ptpn)]2+ and [Ru(phen)2(ptpn)]2+. Dalton Trans 2013, 42, 4386-4397, https://doi.org/10.1039/C3DT32921F.

48. Membrino, A.; Paramasivam, M.; Cogoi, S.; Alzeer, J.; Luedtke, N. W.; Xodo, L. E. Cellular uptake and binding of guanidine-modified phthalocyanines to KRAS/HRASG-quadruplexes. Chem. Commun 2010, 46, 625-627, https://doi.org/10.1039/B918964E.

49. Ren, L.; Zhang, A.; Huang, J.; Wang, P.; Weng, X.; Zhang, L.; Liang, F.; Tan, Z.; Zhou, X. Quaternary Ammonium Zinc Phthalocyanine: Inhibiting Telomerase by Stabilizing G quadruplexes and Inducing G- 
Quadruplex Structure Transition and Formation. Chem Bio Chem 2007, 8, 775-780, https://doi.org/10.1002/cbic.200600554.

50. Dixon, I. M.; Lopez, F.; Estève, J.-P.; Tejera, A. M.; Blasco, M. A.; Pratviel, G.; Meunier, B. Porphyrin Derivatives for Telomere Binding and Telomerase Inhibition. Chem Bio Chem 2005, 6, 123-132, https://doi.org/10.1002/cbic.200400113.

51. Maraval, A.; Franco, S.; Vialas, C.; Pratviel, G.; Blasco, M. A.; Meunier, B.; Porphyrin-aminoquinoline conjugates as telomerase inhibitors. Org Biomol Chem 2003, 1, 921-927, https://doi.org/10.1039/B211634K.

52. Ye, R.; Tan, C.; Chen, B.; Li, R.; Mao, Z. Zinc-containing metalloenzymes: inhibition by metal-based anticancer agents. Front Chem 2020, 8, 402, https://doi.org/10.3389/fchem.2020.00402.

53. Zheng, X.-H.; Cao, Q.; Ding, Y.-L.; Zhong, Y.-F. G.; Qin, M. P. Z.; Ji, L.-N.; Mao, Z.-W.; Platinum(II) clovers targeting G-quadruplexes and their anticancer activities, Dalton Trans. 2015, 44, 50-53, https://doi.org/10.1039/c4dt02760d.

54. Fang, Y.; Osterloh, WR.; Desbois, N.; Pacquelet, S.; Fleurat-Lessard, P.; Gros, CP.; Kadish, K.M. Solvent and Anion Effects on the Electrochemistry of Manganese Dipyrrin-Bisphenols. Inorg Chem 2020, 59, 1591315927, https://doi.org/10.1021/acs.inorgchem.0c02416.

55. Baudron, S.A. Dipyrrin based metal complexes: reactivity and catalysis. Dalton Trans, 2020, 49, 6161-6175, https://doi.org/10.1039/D0DT00884B.

56. Bendix, J.; Gray, H. B; Golubkov, G.; Gross, Z. High-field (high-frequency) EPR spectroscopy and structural characterization of a novel manganese(iii) corrole. Chem Commun 2000, 1957-1958, https://doi.org/10.1039/B006299P.

57. Maraval, A.; Franco, S.; Vialas, C.; Pratviel, G.; Blasco, M. A.; Meunier, B. Porphyrin-aminoquinoline conjugates as telomerase inhibitors. Org Biomol Chem 2003,1, 921-927, https://doi.org/10.1039/B211634K.

58. Bhattacharjee, A. J.; Ahluwalia, K.; Taylor, S.; Jin, O.; Nicoludis, J. M.; Buscaglia, R.; Brad Chaires, J.; Kornfilt, D. J. P.; Marquardt, D. G. S.; Yatsunyk, L. A. Induction of G-quadruplex DNA structure by Zn(II) 5,10,15,20-tetrakis(N-methyl-4-pyridyl)porphyrin. Biochimie $\quad \mathbf{2 0 1 1 ,}$ 93, 1297-1309, https://doi.org/10.1016/j.biochi.2011.05.038.

59. Zhang, L.; Huang, J.; Ren, L.; Bai, M.; Wu, L.; Zhai B.; Zhou, X., Synthesis and evaluation of cationic phthalocyanine derivatives as potential inhibitors of telomerase, Bioorg. Med. Chem. 2008, 16, 303-312. Hhtps://doi.org/10.1016/j.bmc.2007.09.037.

60. Günsel, A.; Bilgiçli, A.T.; Barut, B.; Taslimi, P.; Özel, A.; Gülçin, İ.; Biyiklioglu, Z.; Yarasir, M.N. Synthesis of water-soluble tetra-substituted phthalocyanines: Investigation of DNA cleavage, cytotoxic effects and $\begin{array}{llllll}\text { metabolic enzymes } & \text { inhibition. } & \text { J Mol } & \text { Struct } & \mathbf{2 0 2 0}, & 1214,\end{array}$ https://doi.org/10.1016/j.molstruc.2020.128210.

61. Sun, R. W.-Y.; Li, C. K.-L.; Ma, D.-L.; Yan, J. J.; Lok, C.-N.; Leung, C.-H.; Zhu, N.; Che, C.-M. Stable Anticancer Gold (III)-Porphyrin Complexes: Effects of Porphyrin Structure. Chem - Eur J 2010, 16, 30973113, https://doi.org/10.1002/chem.200902741.

62. Fu, B.; Zhang, D.; Weng, Zhang, X. M.; Ma, H.; Ma, Y.; Zhou, X., Cationic metal-corrole complexes: design, synthesis, and properties of guanine-quadruplex stabilizers, Chem. - Eur. J., 2008, 14, 9431-9441, https://doi.org/10.1002/chem.200800835 .

63. Gershman, Z.; Goldberg, I.; Gross, Z., DNA binding and catalytic properties of positively charged corroles, Angew. Chem., Int. Ed., 2007, 46, 4320-4324, htps://doi.org/10.1002/anie.200700757.

64. Hu, M.-H.; Chen, S.-B.; Wang, B.; Ou, T.-M.; Gu, L.-Q.; Tan, J.-H.; Huang, Z.-S. Specific targeting of telomeric multimeric G-quadruplexes by a new triaryl-substituted imidazole. NAR 2017, 45, 1606-1618, https://doi.org/10.1093/nar/gkw1195.

65. Neidle, S.; Parkinson, G. Telomere maintenance as a target for anticancer drug discovery. Nat Rev Drug Discovery 2002, 1, 383-393, https://doi.org/10.1038/nrd793.

66. Huppert, J. L.Four-stranded nucleic acids: structure, function and targeting of G-quadruplexes. Chem Soc Rev 2008, 37, 1375-1384, https://doi.org/10.1039/B702491F.

67. Duquette, M. L.; Handa, P.; Vincent, J. A.; Taylor, A. F.; Maizels, N. Intracellular transcription of G-rich DNAs induces formation of G-loops, novel structures containing G4 DNA. Genes Dev 2004, 18, 1618-1629, https://doi.org/10.1101/gad.1200804.

68. Campbell, N. H.; Parkinson, G. N.; Reszka, A. P.; Neidle, S. Structural Basis of DNA Quadruplex Recognition by an Acridine. Drug J Am Chem Soc 2008, 130, 6722-6724, https://doi.org/10.1021/ja8016973. 
69. Lin, C.; Wu, G.; Wang, K.; Onel, B.; Sakai, S.; Shao, Y.; Yang, D. Molecular Recognition of the Hybrid-2 Human Telomeric G-Quadruplex by Epiberberine: Insights into Conversion of Telomeric G-Quadruplex Structures. Angew Chem Int Ed Engl 2018, 57, 10888-10893, https://doi.org/10.1002/anie.201804667.

70. Phan, A. T.; Kuryavyi, V.; Gaw, H. Y.; Patel, D.J. Small-molecule interaction with a five-guanine-tract Gquadruplex structure from the human MYC promoter. Nat Chem Biol 2005, 1, 167-173, https://doi.org/10.1038/nchembio723.

71. Armond, R. De.; Wood, S.; Sun, D.; Hurley, L. H.; Ebbinghaus, S. W. Evidence for the Presence of a Guanine Quadruplex Forming Region within a Polypurine Tract of the Hypoxia Inducible Factor $1 \alpha$ Promoter. Biochemistry 2005, 44, 16341-16350.

72. Asamitsu, S.; Obata,S.; Tuân Phan,A.; Hashiya,K.; Bando, T.; Sugiyama,H. Simultaneous Binding of Hybrid Molecules Constructed with Dual DNA-Binding Components to a G-Quadruplex and Its Proximal Duplex. Chem Eur J 2018, 24, 4428-4435, https://doi.org/10.1002/chem.201705945.

73. Monchaud, D.; Allain, C.; Teulade-Fichou, M. P. Development of a fluorescent intercalator displacement assay (G4-FID) for establishing quadruplex-DNA affinity and selectivity of putative ligands. Bioorg Med Chem Lett 2006, 16, 4842-4845, https://doi.org/10.1016/j.bmcl.2006.06.067.

74. Dixon, I. M.; Lopez, F.; Tejera, A. M.; Estve, J. P.; Blasco, M. A.; Pratviel, G.; Meunier, B. A G-Quadruplex Ligand with 10000-Fold Selectivity over Duplex DNA. J Am Chem Soc 2007, 129, 1502-1503, https://doi.org/10.1021/ja065591t.

75. Haudecoeur, R.; Stefan, L.; Denat, F.; Monchaud, D. A Model of Smart G-Quadruplex Ligand. J Am Chem Soc 2013 ,135, 550-553, https://doi.org/10.1021/ja310056y.

76. Panda, D.; Saha, P.; Das, T.; Dash ,J. Target guided synthesis using DNA nano-templates for selectively assembling a G-quadruplex binding c-MYC inhibitor. Nat Commun 2017, 8, https://doi.org/10.1038/ncomms16103.

77. Asamitsu, S.; Obata, S.; Yu, Z.; Bando, T.; Sugiyama, H. Recent Progress of Targeted G-QuadruplexPreferred Ligands Toward Cancer Therapy. Molecules 2019, 24, 429, https://doi.org/10.3390/molecules24030429.

78. Savva, L.; Georgiades, S.N. Recent Developments in Small-Molecule Ligands of Medicinal Relevance for Harnessing the Anticancer Potential of G-Quadruplexes. Molecules 2021, 26, 841, https://doi.org/10.3390/molecules26040841.

79. Shinohara, K.; Sannohe, Y.; Kaieda, S.; Tanaka, K.; Osuga, H.; Tahara, H.; Xu, Y.; Kawase, T.; Bando T.; Sugiyama, H. A Chiral Wedge Molecule Inhibits Telomerase Activity. J Am Chem Soc 2010, 132, 37783782, https://doi.org/10.1021/ja908897j.

80. Mergny, J. L.; Phan, A. T.; Lacroix, L. Following G-quartet formation by UV-spectroscopy. FEBS Lett 1998, 435, 74-78, https://doi.org/10.1016/S0014-5793(98)01043-6.

81. Lubitz, I.; Borovok, N.; Kotlyar, A. Interaction of Monomolecular G4-DNA Nanowires with TMPyP: Evidence for Intercalation. Biochemistry 2007, 46, 12925-12929, https://doi.org/10.1021/bi701301u.

82. Kosiol, N.; Juranek, S.; Brossart, P.; Annkristin H.; Katrin P. G-quadruplexes: a promising target for cancer therapy. Mol Cancer 2021, 20, 40, https://doi.org/10.1186/s12943-021-01328-4.

83. Andreeva, D.V.; Tikhomirov, A.S.; Shchekotikhin, A.E. Ligands of G-quadruplex nucleic acids. Russ Chem Rev 2021, 90, 1, https://doi.org/10.1070/RCR4968.

84. Anantha, N. V.; Azam, M.; Sheardy, R. D. Porphyrin Binding to Quadruplexed T4G4. Biochemistry 1998, 37, 2709-2714, https://doi.org/10.1021/bi973009v.

85. Li, Q.; Xiang, J.; Li, X.; Chen, L.; Xu, X.; Tang, Y.; Zhou, Q.; Li, L.; Zhang, H.; Sun, H.; Guan, A.; Yang, Q.; Yang, S.; Xu, G. Stabilizing parallel G-quadruplex DNA by a new class of ligands: Two non-planar alkaloids through interaction in lateral grooves. Biochimie 2009, 91, 811-819, https://doi.org/10.1016/j.biochi.2009.03.007.

86. Martino, L.; Virno, A.; Pagano, B.; Virgilio, A.; Micco, S. D.; Galeone, A.; Giancola, C.; Bifulco, G.; Mayol, L.; Randazzo, A. Structural and Thermodynamic Studies of the Interaction of Distamycin A with the Parallel Quadruplex Structure [d(TGGGGT)]4. J Am Chem Soc 2007, 129, 16048-16056, https://doi.org/10.1021/ja075710k. 